\title{
Old Shatterhand et les fils* de Tell
}

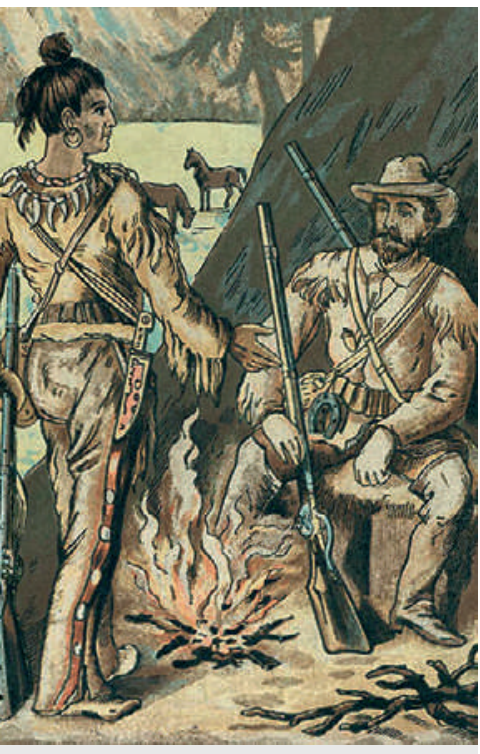

Réussir la communication transculturelle: l'exemple d'Old Shatterhand.
* ainsi que les filles, cela va de soi.

** On me rapporte que les Romands et les Français présentent eux aussi des différences culturelles significatives, bien qu'elles ne semblent pas concerner au premier chef le comportement de communication. Il serait intéressant d'en savoir plus.

1 Diem N, Pill I, Baumann F. Der kleine Unterschied. Interkulturelle Kommunikation zwischen Schweizern und Deutschen in der Medizin. Bull Méd Suisses. 2013;94(1/2):31-3.

bkesseli[at]emh.ch
Mes premières leçons en compétence transculturelle, je les ai reçues de notre maître à tous, l'auteur allemand Karl May, durant mes premières années d'école primaire. Quand Old Shatterhand et Kara Ben Nemsi, ses deux alter ego, négociaient assis autour du feu de camp, l'un avec des Peaux-rouges à la mine patibulaire sur les bords du Pecos, l'autre au Kurdistan avec des fils du désert enturbannés, ils connaissaient exactement le rituel. D'abord, attendre patiemment sans rien se dire, puis tourner au moins une demi-heure autour du pot. S'émerveiller de la beauté de la lune ou des fleurs du désert, admirer la fougue du mustang ou l'endurance du chameau. Après ces préliminaires, on pouvait passer à l'objet proprement dit de la rencontre, qui consistait en règle générale à sauver les scalps des gentils et à régler leur compte aux crapules de tout poil.

De nos jours, c'est sans doute avec un «Master en communication transculturelle» dans leurs bagages que nos héros sillonneraient les prairies ou les dunes. A l'heure de la mondialisation, chacun a pris conscience que le comportement de communication est largement déterminé par des spécificités culturelles, et qu'il peut être crucial de les connaître pour que le message passe.

Plus les différences culturelles sont importantes, mieux on admet qu'il n'est pas évident de se comprendre. La question devient plus épineuse quand les interlocuteurs sont de culture pratiquement identique - ou réputée telle. Comme c'est le cas des Suisses alémaniques et des Allemands. ${ }^{* *}$

Il va de soi que notre propos n'est pas de créer des problèmes où il n'y en a pas. Personnellement - et j'ai beaucoup à faire avec des Allemands à titre professionnel et privé - il me semble qu'en général, nos rapports sont excellents. Pourtant, comme l'a fort joliment décrit un article récemment paru dans le Bulletin des médecins suisses [1], il y a des différences incontestables entre les Suisses alémaniques et les Allemands au niveau du comportement de communication. Si celles-ci suscitent parfois des irritations surtout du côté suisse, cela montre clairement que le problème n'est justement pas si banal. Car les Allemands, pour leur part, s'étonnent de l'irritation des Suisses; ils sont souvent même incapables de se l'expliquer.

Comme l'explique l'article en question, le type de communication direct que privilégient beaucoup d'Allemands peut être perçu en Suisse comme arro- gant ou discourtois. L'un des problèmes est que, loin de nous limiter à un constat neutre («Tiens, ils ne font pas comme nous!»), nous jugeons immédiatement leur comportement de communication divergent à l'aune des règles que nous avons nousmêmes intériorisées. Personne n'oserait affirmer sérieusement que les Allemands en général ont moins de tact ou sont moins cordiaux que les Suisses. Autant prétendre de nous autres Alémaniques que nous sommes tous hypocrites ou obséquieux parce que nous préférons un style de communication indirect. Quand le médecin-chef suisse demande poliment à son assistant s'il serait assez aimable pour aller lui chercher le dossier $\mathrm{X}$ dans les archives, il est évident qu'il ne s'agit pas d'une question. L'assistant le sait très bien, ou se rendrait vite compte de son erreur s'il lui prenait de répondre par exemple: «Désolé, mais là, je suis occupé - allez donc chercher le dossier vous-même.»

J'ai trouvé passionnantes les réactions à l'article de Diem et al. Si les lettres de lecteurs à la rédaction ont été plutôt rares, ce qui m'a surpris, j'ai tout de même reçu quelques commentaires directs dont certains ont débouché sur de longues discussions. Fait intéressant, les Suisses alémaniques avaient tendance à émettre des avis critiques sur l'article: Cela les dérangeait que les Allemands souffrent (trop) de la comparaison de leur comportement de communication avec celui des Suisses. Faut-il y voir une confirmation de la thèse que les Suisses craignent plus que tout de passer pour arrogants, quand bien même leur portrait «élogieux» (qui se voulait sans doute plutôt neutre) émanait d'auteurs allemands? Au contraire, des amis allemands ont trouvé l'article plutôt «amusant» ou «drôle». Loin de réfuter dans un réflexe de rejet le mode de communication directe dont ils sont crédités, ils ont rapporté à leur tour des anecdotes désopilantes qui jetaient une lumière parfois crue sur les facettes problématiques du style de communication suisse-alémanique.

Lors du brunch de la fête des Rois dégusté en famille avec des amis suisses-alémaniques, nous sommes en tout cas tombés d'accord que nos enfants (suisses) profiteraient de ce nous leur transmettions quelques bonnes vertus communicatives «allemandes» pour leur vie future. Même s'ils ont peu de chances de revivre les aventures d'Old Shatterhand et de Kara Ben Nemsi.

Bruno Kesseli 